\title{
THE IMPACT OF A PROPENSITY FOR RELATIONALISM AND MARKET GROWTH ON DISTRIBUTION CHANNEL OUTCOMES
}

\author{
Gregory S. Black \\ Donna K. Peeples \\ Texas A\&M University - Corpus Christi \\ Corpus Christi, TX
}

\begin{abstract}
This research investigates the effects of an organization s propensity for relationalism and its product line market growth on the distribution channel outcomes of actual relationalism and relationship endurance. Using a sample of 160 industrial equipment distributors, propensity for relationalism is shown to have an influence on both actual relationalism and relationship endurance. Further, evidence is found that market growth enhances the impact propensity toward relationalism has on relationship endurance.
\end{abstract}

\section{Introduction}

As the world of business and the state of economy become more uncertain, long-term relationships between distribution channel partners are becoming increasingly more attractive as part of a company's long-term strategy (Ellinger, Ellinger, and Keller 2002; Mentzer, Flint, and Hult 2001). Organizations rely on these ongoing relationships more and more as part of their long-term strategies. By definition, relational exchange between organizations involves a partnership orientation. It may be argued that a transactional strategy, where an organization concentrates on single transactions rather than ongoing relationships with channel partners, is more flexible and thus better than aa long-term relational relationship. Contrarily, current literature continues to find support for relational exchange. Most organizations with this long-term perspective see their channel partners as first-line customers and partners. They practice strong relationship management to forge long-term partnerships with channel members. This creates a marketing system that meets the needs of both the company and its channel partners (Anderson and Narus 2003; Kotler and Armstrong 2006).

Trust and commitment between these partner organizations dominate these arrangements and trust has been shown to be an important factor to make a channel relationship work in a relational fashion (Batt 2003; Cavusgil, Deligonul, and Zhang 2004; Hewett and Bearden 2001; Zhang, Cavusgil, and Roath 2003). Also, in relational exchange, the relationship takes on value that exceeds the benefits resulting from any single transaction or set of transactions (Berthon, Pitt, Ewing, and Bakkeland 2003; Dwyer, Schurr, and Oh 1987; Morgan and Hunt 1994; Siu 2002). Thus, relational exchange, and channel support activities related to 
this relationalism, offer distribution channel partners many advantages, such as enhanced efficiency, streamlined interactions, channel member motivation, channel member satisfaction, and growth (Hausman, 2001; Mehta, Dubinsky, and Anderson 2002; Paswan 2003). In addition, partners in relational exchanges cooperate to enhance effectiveness and productivity in the distribution channel (Frazier, Spekman, and O'Neal 1988, Paswan 2003). Despite the recent trend in many industries toward strategic alliances involving competitors, alliances involving channel members rather than competitors result in more customerorientation and lead to more overall organizational performance (Rindfleisch and Moorman 2003).

Researchers have empirically verified the viability of relational distribution arrangements and the presence of relational norms (e.g., Coughlan and Grayson 1998; Heide and John 1992; Kaufman and Dant 1992; Noble, Sinha, and Kumar 2002; Paswan, Pappu, and Young 2002). Further, the effects of relationalism on important channel phenomena, such as influence wielding (Boyle, Dwyer, Robicheaux, and Simpson 1992) and trust and commitment (Zhang, Cavusgil, and Roath 2003), have been established. Despite these advances, a number of important gaps remain in our understanding of the role and effects of relationalism in marketing channels, including the effects of actual relationalism on channel outcomes and the role that a propensity toward relationalism may play.

With few exceptions (e.g., Johnson and Black 1996; Noordeweir, John, and Nevin 1990), the impact of relationalism on distribution channel performance remains largely unexplored. This constitutes an important gap, given that these relational exchanges are so important to an organization's long-term strategy. The impact of an organization's propensity to engage in these relational channel partnerships has thus far received no research attention. In addition, these types of long-term relationships require significant resources to develop and maintain, so, this propensity for relationalism makes it more likely for an organization to commit these resources and efforts to establish and maintain these long-term channel partnerships. If returns from such arrangements cannot be demonstrated, the competitive position and viability of both the individual organization and the distribution channel eventually will erode. Thus, both researchers and practitioners would benefit from more assessment of the effects of relationalism on interfirm outcomes.

To address this gap in knowledge, this study investigates how an organization's general tendency, or propensity, to engage in relational exchange, rather than discreet transactional exchanges, influences channel outcomes. This research includes duration of the channel relationship and market growth of the major supplier's product line as additional variables of interest for investigation. These variables were selected for several reasons. With regard to supplier's market growth, financial performance is unarguably always a consideration for channel managers. This market growth dimension of financial performance is particularly appropriate for consideration in conjunction with actual relationalism because it is logically related to distributor-supplier joint efforts in market development. 
Duration of the relationship is included in this study because it indicates the closeness and success of the relationship in a general sense. Channel partners cannot enjoy the rewards of the relationship unless they can rely on its endurance (Anderson and Weitz 1989).

In the following sections, relevant literature is reviewed and the concepts included in this research are developed, leading up to a set of hypotheses. An explanation of the methodology is offered and then the results of hypotheses testing are presented. Finally, implications of the research findings conclude the paper.

\section{Hypotheses}

\section{Distribution Channel Outcomes (Dependent Variables)}

Distribution channels fundamentally form to facilitate exchange processes between producers and final customers of products (Alderson 1954). Relational exchange in these channels provides a means of significantly enhancing the smoothness and efficiency of these exchange processes. Relationalism implies that the channel relationship holds value for the participants above and beyond any gains from individual discreet relationships (Macneil 1980). Relationalism is manifest in norms which consist of expectations about patterns of behavior that are shared among the participants in a complex exchange relationship. These relational norms provide for routinized and efficient exchange in channel relationships (Dwyer, Schurr, and Oh 1987). In particular, relational norms provide the organization with flexibility and stability in its interactions with its exchange partners. Further, they provide a way to enhance the benefits or modify the risks associated with distribution channel participation (Stafford 1992). In essence, relational norms are mechanisms that allow channel participants to structure and mold exchange relationships into a desirable framework and these types of relationships take time, resources, and commitment of both partners to develop and succeed (Heide and John 1992; Kaufman and Dant 1992: Paswan and Young 1999).

In various forms, the durability or endurance of the channel relationship has received considerable attention in the literature. Several authors have investigated channel relationship endurance in terms of continuity expectation (e.g., Anderson and Weitz 1989; Heide and John 1990; Noordeweir, John, and Nevin 1990) which constitutes a future-oriented approach. Ganesan $(1993,1994)$ investigated relationship endurance as long-term orientation of the channel participants. As with continuity expectation, an emphasis on long-term orientation is looking to the future; however, it also involves a general preference for enduring relationships. Kumar, Stern, and Achrol (1992) address this facet of interorganizational performance as stability, suggesting that inducing continued membership of channel participants is an important objective for an effective channel member.

Other researchers have included age of the channel relationship as a measure of relationship endurance (e.g., Anderson and Weitz 1989; Heide and John 1990; Heide 1994). Age of the channel relationship indicates stability and closeness. 
The longer a distribution relationship has survived, the more likely partners have come to terms with problem areas in the relationship and the more likely they have worked out systems of coordination and cooperation. In addition, relationship age serves as a proxy for the future-oriented component of relationship endurance. Channel participants who have successfully worked together over time will not readily dismiss the relationship, and will experience significant replacement costs if the relationship fails.

To summarize, the two distribution channel outcomes (dependent variables) investigated in this research are actual relationalism or the extent to which a firm is engaged in relational exchange agreements, and relationship endurance between the distributor and supplier in the distribution channel. The following paragraphs present hypothesized relationships between these channel outcomes and some predictor variables. Figure 1 shows a model summarizing the hypothesized relationships examined in this research.

Figure 1

\section{Model of Predictors of Distribution Channel Outcomes}

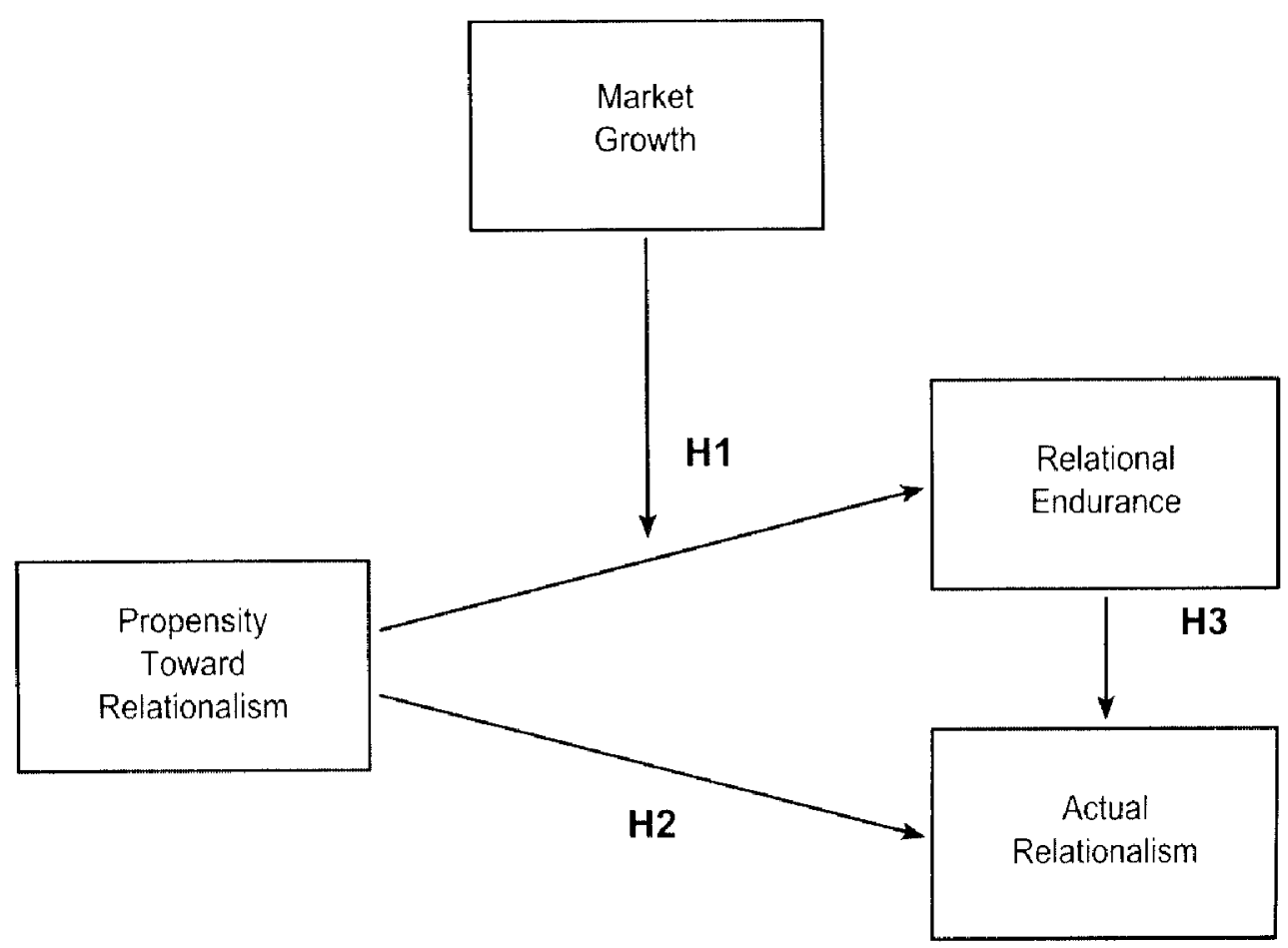

\section{Influences on Distribution Channel Outcomes (Independent Variables)}

Like individuals, organizations may or may not have a propensity to engage in these long-term relational arrangements. Individual people may trust others and engage in many close friendships, while others tend to be untrusting of others and have few close relationships. This general propensity to engage in 
close and long-term relationships also occurs for organizations and is based on experiences with other partner organizations in the past, personalities of its top managers, and other intraorganizational factors, such as corporate culture (Black, Moore, and Vogt 2000). Thus, if an organization possesses a high propensity to engage in relationalism, or the tendency to engage in long-term distribution channel relationships, there is more of a likelihood that its relationship with any distribution channel partner will be longer than for organizations not having this propensity for relationalism.

This influence of propensity for relationalism on relationship endurance should be enhanced by the market growth of the product line that is shared between the channel partners. While financial performance alone does not provide a complete picture of distribution channel performance, it is a necessary concern for channel participants. The organization's perception of its performance orientation is likely to influence its decisions regarding distribution channel management behavior and related activities. In other words, organizations that stress financial goals are likely to result in adopting different distribution channel support activities than organizations that focus on marketing-oriented factors (Noble, Sinha, and Kumar 2002; Paswan 2003; Pelham 1997).

Researchers often address financial performance in terms of profits, revenues, contribution to profits or revenues, or market share (Kerin, Mahajan, and Varadarajan 1990). Another critical, but perhaps somewhat neglected, dimension of financial performance is market growth of a product or product line (Goodman and Pennings 1980; Pelham 1997; Pelham 2000). In an in-depth investigation of reseller performance from the supplier's perspective, Kumar, Stern, and Achrol (1992) considered the organization's ability and need to adapt as an important element of performance. They included growth as one dimension where the firm can demonstrate its ability and willingness to adapt. This suggests that to be effective, channel members must consider growth issues in financial performance. Success in this type of financial performance will further encourage organizations with the propensity toward relationalism to remain in channel relationships for longer durations.

Thus far, with few exceptions (e.g., Johnson and Black 1996), the relationship between relationalism, relationship endurance, and market growth remain largely unexplored. One noteworthy advantage of relational exchange is the streamlined interaction that results. The increased efficiency from streamlined interaction directly translates into reduced distribution costs. In a relational channel arrangement dominated by trust, commitment, and norms of stability, flexibility, and reliability, partners are encouraged to cooperate in joint efforts that reduce distribution costs (Frazier, Spekman, and O'Neal 1988). Channel partners realize they can invest resources in such cost reducing programs because they will reap both joint and individual benefits from the relationship in the future. Reduced distribution cost allows distributors to offer end users more and better products for the purchase price. Enhanced product value should spur market development and market share growth. If the channel partners perceive that these goals are 
actually being met, their efforts will be justified and the relationship is more likely to endure. Thus, actual performance, such as market growth, will enhance the relationship between propensity toward relationalism and relationship endurance. Therefore, the following hypothesis is offered.

Hypothesis 1: The positive effect of the propensity toward relationalism on relationship endurance increases for industrial distribution channel relationships that have higher market growth.

This general tendency to engage in relational exchange (propensity toward relationalism) has important implications in the distribution channel. A propensity toward relationalism means that a channel participant sees significant advantage in actual relationalism and seeks relational types of arrangements. This propensity also suggests that the channel member will build and maintain multiple relational arrangements, perhaps even on multiple fronts, for example, in both input and output sectors. For distributors, a propensity for relationalism signals that the distributor values and desires enduring relationships with suppliers. It indicates that the stability offered by long-term channel relationships is important and that the distributor believes in the advantage of an enduring relationship. Therefore, the resources will be expended and the commitment will be present to establish the relational norms needed to engage in actual relationalism.

From a transaction cost perspective, channel partners are not likely to commit resources or relationship-specific investments in relationships they do not expect to last (Heide and John 1990; Rokkan, Heide, and Wathne 2003). Organizations with a propensity toward relationalism will be more likely to seek out long-term relationships and expect them to last. Channel partners make investments in these relationships because relationalism allows them to realize significantly enhanced economic rewards over the lifetime of the relationship (Dwyer, Schurr, and Oh 1987). Additionally, having committed substantial resources to the relationship, those resources also act as an exit barrier for participants (Heide and John 1992; Rokkan, Heide, and Wathne 2003). Based on this reasoning, the following is hypothesized.

Hypothesis 2: Greater propensity toward relationalism in industrial distribution channel arrangements results in a higher level of actual relationalism.

As organizations remain in channel partnerships for longer durations, the value placed on the relationship and the investments distribution channel participants make in relational distribution arrangements are likely to increase (Noordewier, John, and Nevin 1990). Because of the perceptions of effectiveness and efficiency in relational exchange, and the significant replacement costs, participants are less likely to exit such arrangements (Dwyer, Schurr, and Oh 1987). High levels of 
relationship endurance and the accompanying investments of resources in the relationship comprise an important component in the development of relational exchange in distribution channels ( Dwyer, Schurr, and Oh 1987). Thus, the following hypothesis is proposed.

Hypothesis 3: A higher level of relationship endurance in industrial distribution channels results in a higher level of actual relationalism.

\section{Method}

\section{Sample and Data Collection}

Supplier-distributor relationships in the industrial equipment industry provided the research setting for this study. The setting was limited to distribution relationships in this one industry to restrict extraneous sources of variation, as suggested by previous research (e.g., Heide and John 1992). The industrial equipment distribution channels were deemed appropriate for this study for several reasons. First, through a review of trade publications, it was determined that the constructs and processes being investigated were relevant in this industry. Second, this industry provided a setting where size discrepancy between buyers and sellers was minimized. Third, structures in both the supplier and purchaser markets did not seem to exhibit any anomalies that would bias the study findings. Fourth, these distributors carry an appropriately narrow product line which controls for extraneous factors (e.g., breadth of line) that may impact the level of growth of a single supplier's market share and bias the research findings. Finally, recent research suggests a relational exchange approach becomes even more important among members of a channel that is distributing more complex products (Brait 2004; Gosain and Palmer 2004).

Given that the industry consists of smaller firms in which a single manager performed all or most of the relevant processes, data were collected from single key informants. Qualified key informants were identified through extensive telephone screening. As recommended by Campbell (1955), the informants were qualified on the basis of their specific experience with the phenomenon under investigation and their ability and willingness to communicate their knowledge.

\section{Instrument Development}

Where possible, questionnaire items were derived from relevant literature, with some adjustments for the specific research setting. Multiple items were used to assess actual relationalism, while single items assessed a propensity toward relationalism, growth of the supplier's market share, and relationship endurance.

The preliminary questionnaire draft was administered to several channel participants over the telephone and was adjusted accordingly. Next, the refined questionnaire was reviewed by a panel of questionnaire development experts and 
industrial experts. On the basis of the experts' recommendations, the questionnaire was further refined and was pretested.

From the mailing list of 697 firms, a systematic random sample of 60 distributors was selected for the pretest. The key informant screening process yielded 50 potential respondents. The pretest mailing resulted in 13 completed and usable responses for a response rate of $26 \%$. Though pretest results were generally favorable, they led to the elimination of several items and the rewording of several other items. This new version of the questionnaire was again reviewed by the panel of experts used in a previous step and was further refined. In addition, the pretest was used to modify and refine the telephone screening procedures.

\section{Data Collection}

The initial sampling frame was a national list of every U.S. industrial distributor in this industry. The list consisted of 637 firms, after elimination of the firms used in the pretest. All firms on the sampling frame were screened by telephone. This preliminary screening served two purposes. First, the qualified key informant was identified. Second, having identified the key informant, the telephone contact enhanced the response rate by obtaining prior commitment to participate in the study. Telephone screening resulted in 400 potential respondents.

The data were then collected through a mail survey which proceeded in several stages. First, potential respondents were mailed a pre-notification letter that reminded them of their agreement to participate and described the nature of the research. Second, several days later, the actual questionnaire along with a cover letter and a postage paid return envelope was sent. The cover letter reminded them about the study and assured confidentiality. The initial mailing resulted in 135 responses. One month later, a reminder letter was sent and as a result, an additional 42 responses were received for an overall response rate of $45 \%$. This response is well within the acceptable response rates achieved in similar research (e.g., Boyle et al., 1992; Heide and John 1990, 1992). Of the 177 returned questionnaires, 160 were usable for analysis.

To further insure the quality of the data, two independent tests for response bias were conducted. First, early (up to four weeks after the initial mailing) and late respondents were compared on sales volume, number of employees, age of the relationship, and percentage of sales accounted for by the supplier's products. Second, using secondary data, respondents and non-respondents were compared on sales volume and number of employees. In both cases, t-tests indicated no significant differences. Thus, response bias does not appear to present a problem in this study.

\section{Measures}

Multiple Item Measures. While some researchers (e.g., Dant and Schul 1992; Kaufmann and Dant 1992) have operationalized relationalism in terms of individual relational norms, as outlined by Macneil (1980), this research followed the recommendation of Boyle et al. (1992) and used a global measure of relationalism. 
Five items derived from two previous studies (Boyle et al. 1992; Kaufmann and Dant 1992) were used to assess the level of relationalism. Respondents indicated the extent of their agreement or disagreement with the items on a one (Strongly Disagree) to seven (Strongly Agree) Likert scale. The measure included statements, such as "I consider my firm and our major supplier's firm to be partners in the industry," and "In our business relations with our major supplier, the more powerful firm will use whatever means it can justify to get its own way" (reverse coded).

Single Item Measures. The study also included three single-item variables. The measure of the propensity toward relationalism was derived from information provided by the respondents. First, based on their responses to the relationalism scale, the relationship was classified as relational or discreet. If the relationship was classified as discreet, the propensity toward relationalism score became zero. If the relationship was classified as relational, the propensity toward relationalism score was based on the response to the question, "With how many other organizations do you have similar relations?"

A single question with a categorical response was used to assess growth of the supplier's market share. The question was "Since you began doing business with our major supplier, what is the market growth of the main product line which you get from it?" Respondents indicated their answers by making a check mark in one of seven categories: 1) more than $10 \%$, 2) $8 \%$ to $9.99 \%$, 3) $5 \%$ to $7.99 \%$, 4) $3 \%$ to $4.99 \%$, 5) $1 \%$ to $2.99 \%, 6$ ) $0 \%$ to $0.99 \%$, and 7) no growth, but market shrinkage.

Finally, respondents indicated relationship endurance by answering the question "How long has your organization been doing business with this major supplier?" Data used to assess this variable was the actual length of time indicated by responses to this question.

\section{Data Analysis}

Validity and scale unidimensionality were assessed for the multiple-item measure for relationalism using exploratory factor analysis. Reliability for this multiple item measure was also assessed using Cronbach's alpha. The hypothesized relationships were tested using OLS regression analysis.

\section{Results}

\section{Measure Validation}

Preliminary measure validation consisted of assessments of internal consistency and reliability. Exploratory factor analysis and reliability assessment indicated that the one of the original five items used to measure relationalism should be dropped for the analysis of the hypotheses. After dropping the item, the resulting four-item measurement scale had an acceptable reliability (Cronbach's alpha = .75 ), according to the suggested acceptable level of at least .70 (Nunnally 1978). In addition, exploratory factor analysis with varimax rotation provided evidence 
of scale unidimensionality. The results strongly suggest a single factor solution. This single factor explained $57.3 \%$ of the variance in the relationalism scale and all item loadings were above .63 .

\section{Hypothesis Testing}

Table 1 reports the results of the OLS regression analysis used to test the three hypotheses of this study. In $\mathrm{H}_{1}$, the effect of an organizational propensity toward relationalism on relationship endurance was expected to be enhanced by market growth of the shared product line. First, support was found for propensity toward relationalism positively impacting relationship endurance $(t=2.496, p \leq$ .01 ). As seen in Table 1, when the contingency relationship (propensity toward relationalism * market growth) was added, the relationship was enhanced $(\Delta \mathrm{F}=$ $2.381, \Delta \mathrm{R}^{2}=.133, \mathrm{p} \leq .05$ ). Thus, $\mathrm{H}_{1}$ was fully supported.

\section{Table 1}

Results of Hypotheses Testing

\begin{tabular}{c|c|c|c}
\hline \multicolumn{1}{c}{ Hypothesis } & $\begin{array}{c}\text { Independent } \\
\text { Variables }\end{array}$ & $\begin{array}{c}\text { Dependent } \\
\text { Variable }\end{array}$ & $\begin{array}{c}\text { Test } \\
\text { Statistic }\end{array}$ \\
\hline & $\begin{array}{c}\text { Propensity Toward } \\
\text { Relationalism }\end{array}$ & Relationship Endurance & $\mathrm{t}=2.496^{* *}$ \\
\hline $\mathrm{H} 1$ & $\begin{array}{c}\text { Propensity Toward } \\
\text { Relationalism X } \\
\text { Market Growth }\end{array}$ & Relationship Endurance & $\Delta \mathrm{F}=2.381^{*}$ \\
$\mathrm{H} 2$ & $\begin{array}{c}\text { Propensity Toward } \\
\text { Relationalism }\end{array}$ & Actual Relationalism & $\mathrm{t}=1.985^{*}$ \\
\hline $\mathrm{H} 3$ & Relationship Endurance & Actual Relationalism & $\mathbf{t}=-0949$ \\
\hline
\end{tabular}

$\begin{array}{ll}* & \mathrm{p}<.05 \\ * * & \mathrm{p}<.01\end{array}$

In addition, the propensity toward relationalism was predicted to positively impact actual relationalism in $\mathrm{H}_{2}$. Support was found for this relationship ( $\mathrm{t}=$ $1.985, \mathrm{p} \leq .05$ ), supporting this hypothesis.

Finally, $\mathrm{H}_{3}$ predicts that relationship endurance will have a positive impact on the development of actual relationalism. Table 1 indicates no support for this hypothesis.

\section{Discussion and Implications}

This research extends our understanding of relationalism and its role in distribution channel relationships. This study demonstrates that actual relationalism is 
a worthwhile outcome in distribution channels. Specifically, the results indicate that an organization's propensity toward relationalism results in a higher likelihood that the organization will be involved in an actual relational exchange in an industrial distribution channel. Another interesting finding is that relationship endurance does not have a significant impact on the actual development of relational partnerships. Surprisingly and contrary to expectations, a long-term relationship in an industrial distribution channel does not necessarily invoke the commitment of resources to develop relational norms and trust. One possible reason for this is that certain channel partners in the industrial equipment industry may be so specialized or have so much expertise that there are few alternatives. This situation would result in long relationship endurance, but not necessarily the development of a relational arrangement between the channel partners.

Perhaps other factors (e.g., uncertainty of power asymmetries) not included in this study moderate the relationship. Another possibility is that relationship endurance alone does not provide a sufficiently refined measure of relationship durability. A more complete picture of relationship durability which includes continuity expectations or long-term orientation might reveal more. These concepts disclose more about participants' psychological states regarding the channel relationship. However, this result still seems anomalous since these psychological states should be manifest in behaviors; for example, positive psychological states should induce a continued relationship.

As expected, a firm's general tendency to engage in relational exchange influences relationship endurance. It may be true that firms with a proclivity for relational arrangements may find themselves spread thin in managing and maintaining multiple intense and close relationships that require large amounts of resources. However, firms that are successful in developing and maintaining many productive relationships with distribution channel partners likely possess certain skills and knowledge in managing these relationships that overcome the shortage of resources that may occur. These organizations believe in the payoff of relational exchange and make the necessary commitments, perhaps even in multiple sectors of their business.

The impact of the propensity toward relationalism on relationship endurance is enhanced by performance (market growth). If an organization has high propensity toward relationalism, enhanced performance will likely reinforce this part of the organization's character or culture. This positive psychological reinforcement likely extends to the channel members that contributed to the performance. This, in turn, makes it more likely that the channel relationships between firms with the propensity for relationalism that are actually financially successful are likely to last longer.

For managers, perhaps the major implication of this study is the payoff of relational exchange, both the propensity for relationalism and actual relationalism. It is indeed worthwhile to commit time and resources to developing and maintaining close working relationships with distribution channel partners. Actual performance enhances the likelihood of firms with a tendency to engage in 
relational exchanges to be in more long-term distribution channel relationships. These relational arrangements may even occupy a position of strategic importance in the organization's overall position (Webster 1992). As with all important strategic investments, these relationships should be a top priority for managers, particularly in situations of high firm interdependence. In fact, scholars predict the emergence of networks of functionally-specialized organizations in which the marketer will be only one participant. Interactions among the firms in this network will be largely driven by relational norms and dominated by relational exchange (Achrol 1991).

An organization's penchant for and belief in relational exchange will facilitate the building of more long-term channel relationships. As managers engage in and build more of these relationships, their skills and knowledge in developing and managing relational exchange will increase. The subsequent use of this skill and knowledge will serve them well in other channel relationships. Managers will learn how to make more enduring partnerships with other channel participants.

As in all research, this study has its limitations. The study was limited to one industry, so the findings may not be completely generalizable to distribution channels in other industries. This limitation becomes more significant if the industry studied in this research is dominated by highly-specialized channel partners so few alternatives are available. These findings should be replicated in other industries and other research settings, such as those involving consumer products. In addition, there is still very little knowledge about dependence and relational exchange in international distribution relationships.

\section{References}

Achrol, R. (1991). Evolution of the marketing organization: New forms for turbulent environments. Journal of Marketing. 55, 77-93.

Alderson, W. (1954). Factors governing the development of marketing channels. In R.M. Clewett (Ed.), Marketing channels for manufactured products (pp. 5-22). Homewood, IL: Richard D. Irwin Publishing Company.

Anderson, E. \& Weitz, B. (1989). Determinants of continuity in conventional industrial channel dyads. Marketing Science, 8, 310-323.

Anderson, J.C \& Narus, J.A. (2003, July). Supply chain challenges. Harvard Business Review, 65-73.

Batt, P.J. (2003). Building trust between growers and market agents. Supply Chain Management, $1(8), 65-78$.

Berthon, P., Pitt, L.F., Ewing, M.T., \& Bakkeland, G. (2003). Norms and power in marketing relationships: Alternative theories and empirical evidence. Journal of Business Research, 56(9), 699-711. 
Black, G.S., Moore, R.T., \& Vogt, J.F. (2000). Dispositional trust: A key for international partnering. Academy of Business Administration's 2000 Global Business Trends Conference Proceedings, 10-15.

Boyle, B., Dwyer, F.R., Robicheaux, R., \& Simpson, J. (1992). Influence strategies in marketing channels: Measures and use in different relationship structures. Journal of Marketing Research, 29, 462-473.

Brait, R.A. (2004). Transactional aspects of corporate intellectual property strategy. The Canadian Business Law Journal, 41, 19-26.

Campbell, D. (1955). The informant in quantitative research. American Journal of Sociology, 60, 339-342.

Cavusgil, S.T., Deligonul, S., \& Zhang, C. (2004). Curbing foreign distributor opportunism: An examination of trust, contracts, and the legal environment in international channel relationships. Journal of International Marketing, 12, 7-21.

Coughlan, A.T. \& Grayson, K. (1998). Network marketing organizations: Compensation plans, retail network growth, and profitability. International Journal of Research in Marketing, 15(4), 401-426.

Dant, R. \& Schul, P. (1992). Conflict resolution processes in contractual channels of distribution. Journal of Marketing, 56, 38-54.

Dwyer, F., Schurr, P., \& Oh, S. (1987). Developing buyer-seller relationships. Journal of Marketing, 5I, 11-27.

Ellinger, A.E., Ellinger, A.D., \& Keller, S.B. (2002). Logistics manager's learning environments and firm performance. Journal of Business Logistics, 23(1), 19-37.

Frazier, G., Spekman, R., \& O'Neal, C. (1988). Just-in-time exchange relationships in industrial markets. Journal of Marketing, 52, 52-67.

Ganesan, Shankar. (1993). Negotiation strategies and the nature of channel relationships. $J M R$, Journal of Marketing Research. 30(2), 183-203.

Ganesan, Shankar. (1994). Determinants of long-term orientation in buyer-seller relationships. Journal of Marketing, 58(2), 1-19.

Goodman, P. \& Pennings, J. (1980). Critical issues in assessing organizational effectiveness. In E.E. Lawler, D.A. Nadler, \& C. Cammann (Eds.), Organizational assessment: Perspectives on the measurement of organizational behavior and the quality of work life. (pp.185-215). New York: John Wiley and Sons,.

Gosain, S. \& Palmer, J.W. (2004). Exploring strategic choices in marketplace positioning. Electronic Markets, 14(4), 308-318. 
Hausman, A. (2001). Variations in relationship strength and its impact on performance and satisfaction in business relationships. The Journal of Business \& Industrial Marketing, 16(6/7), 600-616.

Heide, J. (1994). Interorganizational governance in marketing channels. Journal of Marketing. 58, $71-85$.

Heide, J. \& John G. (1990). Alliances in industrial purchasing: The determinants of joint action in buyer-seller relationships. Journal of Marketing, 52, 20-35.

Heide, J. \& John, G. (1992). Do norms matter in marketing relationships? Journal of Marketing, 56, 32-44.

Hewett, K. \& Bearden, W.O. (2001). Dependence, trust, and relational behavior on the part of foreign subsidiary marketing operations: Implications for managing global marketing operations. Journal of Marketing, 65, 51-66.

Johnson, J.L. \& Black, G.S. (1996). The effects of relationalism and supplier replaceability on industrial distribution channel outcomes. Journal of Marketing Channels, $5(2), 25-44$.

Kaufmann, P. \& Dant, R. (1992). The dimensions of commercial exchange. Marketing Letters, 3(2), 171-185.

Kerin, R., Mahajan, V., \& Varadarajan, P. (1990). Contemporary perspectives on strategic market planning. Boston: Allyn and Bacon.

Kotler, P. \& Armstrong, G. (2006). Principles of Marketing, (1 $11^{\text {th }}$ ed.). Upper Saddle River, NJ: Prentice-Hall.

Kumar, N., Stern, L., \& Achrol, R. (1992). Assessing reseller performance from the perspective of the supplier. Journal of Marketing Research, 29, 238-253.

Macnei1, I. (1980). The new social contract. New Haven, CT: Yale University Press.

Mehta, R, Dubinsky, A.J., \& Anderson, R.E. (2002). Marketing channel management and the sales manager, Industrial Marketing Management, 3I(4), 429-439.

Mentzer, J.T., Flint, D.J., \& Hult, G.T.M. (2001). Logistics service quality as a segmentcustomized process. Journal of Marketing, 65, 82-104.

Morgan, R. \& Hunt, S. (1994). The commitment-trust theory of relationship marketing. Journal of Marketing, 58, 20-38.

Noble, C.H., Sinha, R.K., \& Kumar, A. (2002). Market orientation and alternative strategic orientations: A longitudinal assessment of performance implications. Journal of Marketing, 66, 253-259. 
Noordeweir, T. John, G., \& Nevin, J. (1990). Performance outcomes of purchasing arrangements in industrial buyer-vendor relationships. Journal of Marketing, 51, 80-93.

Nunnally, J. (1978). Psychometric theory. New York: McGraw Hill.

Paswan, A.K. (2003). Channel support activities and perceived goal orientation: An exploration in the Indian market. Asia Pacific Journal of Marketing and Logistics, 15(4), 19-41.

Paswan, A.K., Pappu, M., \& Young, J.A. (2002). Relational norms and goal orientation in the Indian market. Journal of International Consumer Marketing, 15(l), 53-67.

Paswan, A.K. \& Young, J.A. (1999). An exploratory examination of the relationship between channel support mechanisms and relational norms in an international context. The Journal of Business \& Industrial Marketing, 14(5/6), 445-459.

Pelham, A.M. (2000). Market orientation and other potential influences on performance in small and medium-sized manufacturing firms. Journal of Small Business Management, 38(1), 48-67.

Pelham, A.M. (1997). Mediating influences on the relationship between marketing orientation and profitability in small industrial firms. Journal of Marketing Theory and Practice. (Summer), 55-76.

Rindfleisch, A. \& Moorman, C. (2003). Interfirm cooperation and customer orientation. Journal of Marketing Research, 40, 421-432.

Rokkan, A.I., Heide, J.B., \& Wathne, K.H. (2003). Specific investments in marketing relationships: Expropriation and bonding effects. Journal of Marketing Research, $40,210-223$.

Siu, W.S. (2002). Marketing activities and performance: A comparison of the internetbased and traditional small firms in Taiwan. Industrial Marketing Management. 31(2), 177-188.

Stafford, E. (1992). Implications of strategic alliance structure: A cooperative strategy relational exchange framework. American Marketing Association's Summer Educators 'Enhancing Knowledge Development in Marketing Conference Proceedings. 3, 101-107.

Webster, F.E., Jr. (1992). The changing role of marketing in the corporation. Journal of Marketing, 56, 1-17.

Zhang, C.W., Cavusgil, S.T., \& Roath, A.S. (2003). Manufacturer governance of foreign distributor relationships: Do relational norms enhance competitiveness in the export market? Journal of International Business Studies, 34(6), 550-559. 
Gregory S. Black is Assistant Professor of Marketing at Texas A\&M University - Corpus Christi. He holds a Ph.D. in Marketing from Washington State University and an MBA from Brigham Young University. He also holds BAs in both International Relations and Korean from Brigham Young University. He has been studying distribution channel phenomenon for over a decade, beginning with his doctoral dissertation.

Donna K. Peeples is Assistant Professor of Management at Texas A\&M University - Corpus Christi. She holds a Ph.D. from Texas A\&M University College Station and an MBA from Texas A\&M University - Corpus Christi. Her research interests include management strategy, consumer behavior, and consumer and Internet privacy. 